\title{
PWM-Based Optimal Model Predictive Control for Variable Speed Generating Units
}

\author{
L.Bigarelli, A.Lidozzi, M. di Benedetto, L. Solero \\ Roma Tre University \\ C-PED, Center for Power Electronics \\ and Drives \\ Rome, Italy \\ luca.bigarelli@uniroma3.it
}

\author{
S.Odhano, P. Zanchetta \\ Dept. of Electrical and Electronic \\ Engineering \\ University of Nottingham \\ Nottingham, UK \\ shafiq.odhano@nottingham.ac.uk
}

\begin{abstract}
This paper investigates the DC-link voltage control of an active rectifier that is supplied by a variable speed permanent magnet synchronous generator. This configuration is commonly encountered in gearless wind energy conversion systems as well as in variable speed generating units. The proposed control strategy uses an optimal voltage vector based modulated model predictive control to achieve direct power control. The studied scheme combines the advantages of finite control set Model Predictive Control (MPC) and control techniques that use pulse width modulator. The fast dynamics of the former are obtained during large transients and constant switching frequency operation, of the latter, is ensured in steady state. At each sampling instant, all switching states are evaluated and the two adjacent states that give minimum error in the controlled variables are selected. The duty-cycle of each of these vectors is computed through linear combination and appropriately limited for over-modulation. Simulations and Co-simulation results presented in the paper show interesting results. The control strategy has been developed on an FPGA control platform and experimental results at steady state are shown, with the aim to demonstrate the computational feasibility of the control strategy.
\end{abstract}

Keywords-permanent magnet synchronous generator, direct power control, modulated model predictive control, optimal voltage vectors.

\section{INTRODUCTION}

Permanent magnet (PM) machines are generally employed for servo and traction applications [1]. In variable speed drives, they are a viable solution in applications that demand high power density, such as integrated starter generators in aerospace sector [2]. These machines are also very effective in gearless wind energy conversion systems where bulky mechanical gearboxes are avoided for minimizing load on wind turbine towers [3]-[5]. With a direct-drive (gearless) permanent magnet synchronous generator (PMSG), a varying wind speed means variable frequency ac voltages being induced at the generator terminals. To be able to couple this variable frequency source with a constant frequency grid, a power electronic interface is necessary.

Most often, the power electronic interface consists of a diode rectifier feeding a dc-link at the output of which another power electronic converter delivers power to the grid [6]. However, a discontinuous conduction pattern in diode bridge rectifiers means greater current ripple and, hence, a substantial torque ripple at the shaft [6]. An active front end (AFE) converter that replaces diodes with bidirectional power electronic switches alleviates this discontinuous conduction problem. The control of this AFE converter has been widely reported in the literature [7]-[11].

An increasing research effort is directed towards MPC applications for AFE control [7], [8]. A ripple-reduced model predictive direct power control of an AFE is presented in [7]. The active and reactive power slopes are determined based on the system state equations. Using these power slopes, the active and reactive powers for the next sampling instant are predicted for seven voltage vectors corresponding to available states of a three-phase inverter. A cost function is evaluated that compares the reference and predicted powers. Unlike finite control states FCS-MPC in which only one voltage vector is applied, [7] uses two vectors whose duties are computed through analytical solution. It should be noted that this technique either applies two active vectors or one active and one zero vector in a control period. Use of two active and a zero vector in the same control period is not analyzed. Dutycycles are optimized in [8] for model predictive current control of an AFE. The control is implemented in $d q$ rotating reference frame. In a given sector, errors in controlled currents are evaluated for the two voltage vectors at the sector boundary. An optimization problem is solved to compute duty-cycles for each active vector in the current sector, which is then transformed to phase duty cycles. Performance of this predictive duty-cycle algorithm is compared with deadbeat, FCS-MPC and linear controllers.

A predictive hybrid pulse width modulation strategy is introduced in [9] for AFEs. The method focuses on minimization of current distortions and switching losses at each sampling instant. Predictive control is used to estimate current distortions and switching losses for every PWM sequence and the sequence that minimizes the cost function is chosen. As such, the control strategy does not deal with the dynamics of control. The application of predictive direct power control to minimize ripple in active power is presented in [10]. Starting from a conventional MPC that identifies the voltage vector with minimum power error, instead of applying this vector for a complete control period its duty-cycle is computed that results in reduced active power ripple. For the remaining time of a control period a zero vector is applied. Thus, only one active vector is used in a given control period. In [11] a performance comparison of different MPC strategies for an AFE rectifier is presented. The performance is analysed in terms of the total harmonic distortion of the line current under different operating conditions, such as unbalanced input 
voltages, uncertainty in the parameters and DC-link voltage fluctuation. The control performance is evaluated for a system with a $10 \mathrm{mH}$ input filter inductance, $1.1 \mathrm{mF}$ output filter capacitance, $60 \mathrm{~Hz}$ frequency and $20 \mathrm{kHz}$ switching frequency.

In this paper, the control of an active front end power converter is implemented through optimal voltage vector selection starting from the basic model predictive control algorithm. The control strategy is adapted from [12], however, the implementation takes place in the rotating $d q$ reference frame. The system under consideration is a variable speed PMSG supplying a DC load. In [7]-[12], the MPC is implemented for AFE rectifiers in systems that present phase inductance values from few to dozens $\mathrm{mH}$ and fundamental frequency of $50 \mathrm{~Hz}$. The aim of this paper is to show the effectiveness of the proposed solution for PMSG with phase inductance and fundamental frequency of about thousands $\mu \mathrm{H}$ and $\mathrm{Hz}$ respectively, as is the case of the PMSG employed in variable speed generation applications, where the increase in the fundamental frequency value allows to reduce the size and the weight of the electric machine and of the overall system. Furthermore, the performance of an MPC control algorithm is strongly affected by the accuracy of the system model. Particularly, when power balances are considered in the control algorithm, it becomes important to realize a model capable of providing good power losses estimation. With respect to the [13], an improved system model, shown in the next section, has been implemented in order to increase the accuracy of the system state estimation.

Starting from the discrete equations of the considered system, the power errors at the next sampling instant are predicted for all the inverter states. Then, the two adjacent inverter states that minimize the error in the active and reactive powers are selected. The duty-cycle for the application of each state is decided by whether it is possible to reach the reference power values in one sampling instant or not. In the first case, when the reference power can be achieved in one sample time, the solution lies in the linear regulation range and the dutycycles are computed through linear combination of the two inverter states. In case the system constraints do not allow reaching the target in one sample time, the over-modulation condition is encountered. To preserve optimality condition also in over-modulation, the duty-cycles for each state are linearly scaled. In this way, the algorithm preserves the fast dynamic characteristics of FCS-MPC as well as maintains constant switching frequency of modulator based control schemes [13]. An advantage of the proposed MPC is that the optimal control action is obtained without explicitly formulating the cost function. This means that no tuning action on the cost function weights is required. Finally, the use of an additional sensor to measure the load current can be avoided implementing an estimator, such as virtual flux methods with low passive filters, state observer and Kalman filters [14].

\section{SYSTEM MODELING}

With respect to the dq0 rotating frame, the equations representing the continuous time model of the PMSG (1) are considered together with the equation describing the DC-link capacitor dynamics, where $i_{c p}$ stands for the capacitor current, as represented in Fig. 1. Applying the Kirchoff law to the node "A" in Fig. 1, the capacitor current is expressed as the algebraic sum between the rectified current $i_{d c}$ and the load current $i_{l}$.

$$
\left\{\begin{array}{l}
L_{d} \frac{d i_{d}}{d t}=v_{s d}-R_{s} i_{d}+\omega L_{q} i_{q} \\
L_{q} \frac{d i_{q}}{d t}=v_{s q}-R_{s} i_{q}-\omega L_{d} i_{d}-\omega \lambda_{p m} \\
C \frac{d v_{d c}}{d t}=i_{c p}
\end{array}\right.
$$

From the continuous time model, forward Euler method is applied to obtain the discrete time model of the system (2). Where $T_{s}$ is the sampling period, $R_{s}$ is the generator phase resistance, $L_{d}$ and $L_{q}$ are the machine inductances, $\mathrm{C}$ the total DC-bus capacitance, $\lambda_{p m}$ is the magnetic flux, $\omega$ is the frequency of the electrical quantities and $v_{s d} v_{\mathrm{sq}}$ are the control actions applied by the inverter to the system.

$$
\begin{aligned}
& i_{d}^{(k+1)}=\left(1-T_{s} \frac{R_{s}}{L_{d}}\right) i_{d}^{(k)}+v_{s d}^{(k)} \frac{T_{s}}{L_{d}}+i_{q}{ }^{(k)} \omega T_{s} \frac{L_{q}}{L_{d}} \\
& i_{q}^{\left({ }^{(k+1)}\right.}=\left(1-T_{s} \frac{R_{s}}{L_{q}}\right) i_{q}{ }^{(k)}+v_{s q}^{(k)} \frac{T_{s}}{L_{q}}-i_{d}{ }^{(k)} \omega T_{s} \frac{L_{q}}{L_{d}}-\omega T_{s} \frac{\lambda_{p m}}{L_{q}} \\
& v_{d c}^{(k+1)}=v_{d c}^{(k)}+\frac{T_{s}}{C}\left(i_{d c}{ }^{(k)}-i_{l}\right)
\end{aligned}
$$

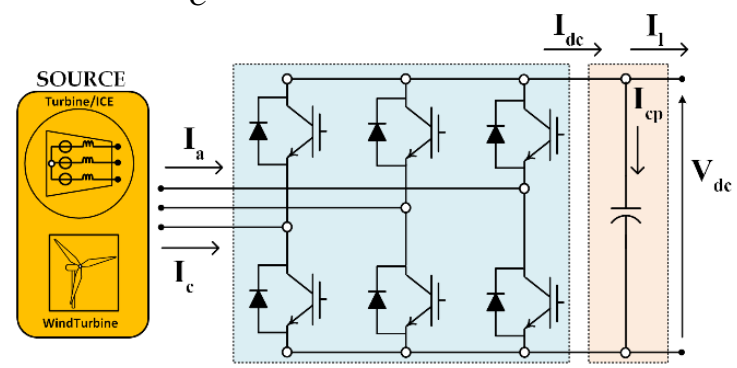

Fig. 1. System representation.

For a given DC-link voltage, the voltage vector resulting from each inverter state is given by (3).

$$
\vec{v}_{s}^{1,7}=v d c\left(\begin{array}{ccc}
0.66667 & -0.3333 & -0.3333 \\
-0.66667 & 0.3333 & 0.3333 \\
-0.3333 & 0.6667 & -0.3333 \\
0.3333 & -0.66667 & 0.3333 \\
-0.3333 & -0.3333 & 0.66667 \\
0.3333 & 0.3333 & -0.66667 \\
0 & 0 & 0
\end{array}\right)
$$

\section{A. Improved modeling and calculations}

In order to accurately control the DC-link voltage, especially during the steady-state condition, an improved modelling approach has been performed to consider more non-ideal effects. Additional losses that have been considered are related to the inverter conduction and switching effects as well as electrical machine joule and iron losses. Those terms will be part of the proposed control structure.

- Electrical machine joule losses

Electrical machine joule losses can be achieved by considering the dq-axes currents that are used also in the control structure. Losses evaluated at the next time step have the expression reported as follows

$$
P_{\text {Jloss }}=\frac{3}{2} R_{s}(T)\left[i_{d,[k+1]}^{2}+i_{q,[k+1]}^{2}\right]
$$

Where also the temperature of the machine stator winding has been taken into account. 


\section{- Electrical machine iron and friction losses}

In order to achieve the aforementioned loss contribution, two different approaches can be used. The first one allows to directly evaluate the whole losses by a no-load test of the electrical machine at the test bed. The use of a torque meter is mandatory to obtain the shaft torque and speed. On the other side, taking into account the design and assembly characteristics, iron and friction losses can be estimated [15], [16].

\section{- Power converter losses}

Power devices losses have been calculated on-line with specific reference to $\mathrm{SiC}$ MOSFET conduction and switching losses, DC-bus capacitors losses as well as freewheeling diodes losses [17]-[19]. Temperature dependency is also taken into account, adjusting losses accordingly.

Aforementioned terms are evaluated on-line during the execution of the main Predictive Control algorithm. In fact, as it will be shown in details later on, the control platform is able to run the MPC controller in parallel with the system losses evaluation block.

\section{MODUlATED MPC STRATEGY}

The purpose of the proposed control strategy is to regulate the DC-link voltage while keeping the reactive power to zero. The desired value of the DC voltage is reached considering the link between the active power flow produced by the PMSM and the change in the capacitor voltage. This relation allows to determine the reference of the q-axis current which enables the achievement of the desired DC voltage. Once that the current references are obtained, the control algorithm must determine the voltage vector that the converter has to apply to the system in order to reach the desired current references and consequently the desired DC voltage. As already known, the only possible control actions in FCS-MPC are those generated by the eight different converter states. The control action is thus discrete, resulting in a low power quality at steady state. In this paper, an inversion of the electrical model is performed as in [12]. Finding an analytical inversion would require extremely high computational effort. The electrical model inversion is thus obtained through linear approximation. Fig. 2 shows the hexagon created by the converter finite control actions on the $\alpha \beta$ plane. Applying to the system each one of these control voltages would result in different values of the $d q$ axes currents. It is then possible to consider the plane of axes $e_{i d}$ and $e_{i q}$, where $e_{i d}$ stands for the error between the predicted values of $i_{d}$ and its reference and $e_{i q}$ represents the error on the q-axis current. The coordinates of each point represented in the plane $e_{i d} e_{i q}\left(e_{1}, e_{2} ..\right)$ stand for the currents that would be present in the system if the voltage vectors with the same index $\left(V_{1}, V_{2} \ldots\right)$ were applied by the converter. On the plane $e_{i d} e_{i q}$ the predictions associated to the non-zero voltage vectors form an irregular hexagon.

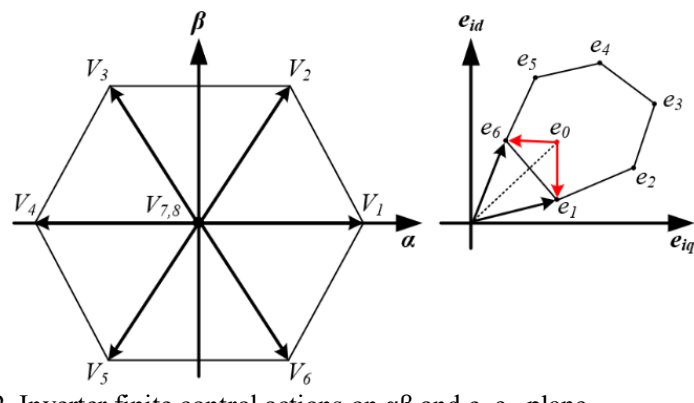

Fig. 2. Inverter finite control actions on $\alpha \beta$ and $\mathrm{e}_{\mathrm{iq}} \mathrm{e}_{\mathrm{id}}$ plane.
The $e_{0}$ error is the one associated to the uncontrolled system, whose evolution is here assumed equal to that of the system when the zero-voltage vector is applied. This means that the point $e_{0}$ represents the initial condition of the system at the beginning of the sampling period. The algorithm is meant to find a linear combination of two adjacent voltage vectors $\left(\vec{v}_{x}, \vec{v}_{y}\right)$ which allows to move in a control period, on the $e_{i d} e_{i q}$ plane, from the point $e_{0}$ to the origin of the coordinate reference system; the latter is the point for which the error between the predicted currents and the reference values goes to zero. The error vectors $\left(\vec{e}_{x}, \vec{e}_{y}\right)$ must then satisfy the following mathematical conditions, which guarantee that the chosen voltage vectors cause the system operating point to move towards the origin of the coordinate reference system:

$$
\begin{aligned}
& \left\{\begin{array}{l}
\left(\vec{e}_{x}-\vec{e}_{0}\right) \cdot\left(-\vec{e}_{0}\right)>0 \\
\left(\vec{e}_{y}-\vec{e}_{0}\right) \cdot\left(-\vec{e}_{0}\right)>0 \\
\left(\vec{e}_{x}-\vec{e}_{0}\right) \times\left(-\vec{e}_{0}\right) \cdot\left(\vec{e}_{y}-\vec{e}_{0}\right) \times\left(-\vec{e}_{0}\right)<0
\end{array}\right. \\
& \left\{\begin{array}{l}
\left(\vec{e}_{x}-\vec{e}_{0}\right) \cdot d_{x}+\left(\vec{e}_{y}-\vec{e}_{0}\right) \cdot d_{y}=\vec{e}_{0} \\
d_{x}+d_{y} \leq 1
\end{array}\right.
\end{aligned}
$$

In Figure 2 the vectors $\left(\vec{e}_{x}-\vec{e}_{0}\right),\left(\vec{e}_{y}-\vec{e}_{0}\right)$ are represented in red. The first two inequalities reported in (4) state that the above-mentioned vectors must have positive components along the $-\mathrm{e}_{0}$ direction, while the third inequality guarantees that their components along the normal to the $-\mathrm{e}_{0}$ direction are of opposite sign. It is then guaranteed that the linear superposition of the two chosen voltage vectors allows to move toward the origin of the coordinate reference system along the $-\mathrm{e}_{0}$ direction. Once the couple of adjacent voltage vectors is chosen, the duty-cycle associated to each of them is calculated, according to the resolution of the linear system expressed by (5). If the sum of the duty cycles determined by (5) is less than 1, the zero-voltage vector is applied for the remaining time of the control period. In the over-modulation region, that is when, $d_{x}+d_{y}>1$, duty-cycles are opportunely scaled according to (6).

$$
\begin{gathered}
d_{x}^{s}=\frac{d_{x}}{d_{x}+d_{y}} d_{y}^{s}=\frac{d_{y}}{d_{x}+d_{y}} \\
\vec{v}_{s}=\vec{v}_{x} d_{x}+\vec{v}_{y} d_{y}
\end{gathered}
$$

The resulting voltage vector applied to the system can be expressed as in (7). The proposed control strategy does not consider an explicit formulation of a cost function, being the control action chosen on the basis of the explained mathematical procedure. The latter aims to identify the two voltage vectors that, linearly combined, lead to the smallest error in the controlled quantities. In order to keep the reactive power equal to zero, $i_{d}$ reference value is set to zero, while to opportunely regulate the capacitor voltage, a reference value of the q-axes current is generated $\left(i_{q, R}\right)$, based on the estimation of the active power flow needed to both feed the load and follow the voltage reference [20]. The control algorithm starts computing the first step of prediction on the basis of the previous control action applied to the system. The values of $i_{d,[\mathrm{k}+1]}, i_{q,[\mathrm{k}+1]}$, and $v_{d c},[\mathrm{k}+1]$ are then calculated. The predicted value of the capacitor voltage $v_{d c},[\mathrm{k}+1]$ is obtained estimating the DC current $i_{d c}$ as a function of the inverter states applied to the system and the phase currents, as shown in (8). This solution is considered because of the specific nature of the proposed MPC strategy, which returns as a result different 
converter states to be applied in a single control period. The adopted solution allows improving the $i_{d c}$ estimation and consequently the whole control algorithm. Second step of prediction starts with the calculation of the $i_{q, R}$ reference value.

$$
i_{d c, M}=\vec{s}_{x}\left(\begin{array}{l}
i_{a} \\
i_{b} \\
i_{c}
\end{array}\right) d_{x}+\vec{s}_{y}\left(\begin{array}{l}
i_{a} \\
i_{b} \\
i_{c}
\end{array}\right) d_{y} \quad \vec{s}=\left(\begin{array}{ccc}
1 & 0 & 0 \\
0 & 1 & 1 \\
0 & 1 & 0 \\
1 & 0 & 1 \\
0 & 0 & 1 \\
1 & 1 & 0 \\
0 & 0 & 0
\end{array}\right)
$$

To do that, a proper power balance is defined considering that the active power flow produced by the PMSG $\left(P_{a g}\right)$ has to account for both the power required by the load $\left(P_{L}\right)$, the power needed to change the DC-link voltage $\left(P_{c}\right)$ and the power losses. Equations (9) describe the existing relation between the change in the stored energy of a capacitor $\left(\Delta E_{c}\right)$ and its voltage variation, as well as the resulting power flow.

$$
\Delta E_{c}=\frac{C}{2}\left(V_{d c, R}^{2}-V_{d c,[k+1]}^{2}\right) P_{c}=\frac{\Delta E_{c}}{T_{t}}
$$

The power required by the load is determined as the product of the load current, which is here assumed measurable, and the desired DC-link voltage. Power losses are considered as Joule losses due to the stator resistance $\left(P_{\text {Jloss }}\right)$, iron losses in the stator system $\left(\mathrm{P}_{\text {Sloss }}\right)$ and the converter switching and conduction losses $\left(\mathrm{P}_{\text {Closs }}\right)$. The sum of the considered losses is $\mathrm{P}_{\mathrm{Ltot}}$. It means that the required active power flow at instant $[\mathrm{k}+2]$ is:

$$
P_{a g,[k+2]}=\frac{C}{2 T_{t}}\left(V_{d c, R}^{2}-V_{d c,[k+1]}^{2}\right)+\left(V_{d c, R} i_{l}\right)+P_{L t o t}
$$

The active power produced by the PMSG is expressed in terms of the q-axes current by (11) and it is then possible to evaluate the $i_{q}$ reference through (12).

$$
\begin{aligned}
& P_{a g}=\frac{3}{2} p \lambda_{p m} \omega_{m} i_{q} \\
& i_{q}^{R}=-\frac{1}{3}\left[\frac{\frac{C}{T_{t}}\left(V_{d c, R}^{2}-V_{d c,[k+1]}^{2}\right)+2 V_{d c,[k+1]} i_{l}+2 P_{L t o t}}{p \lambda_{p m} \omega_{m}}\right] \\
& \begin{array}{|c|}
\hline \text { First Step Of Prediction } \\
\mathbf{i}_{\mathrm{d},[\mathrm{k}+1]} \mathbf{i}_{q,[\mathrm{k}+1]} \mathbf{V}_{\mathrm{dc},[\mathrm{k}+1]} \\
\hline
\end{array} \\
& \begin{array}{|c|}
\hline \mathbf{I}_{\mathrm{qR}} \text { Calculation } \\
\mathbf{P}_{\text {Jlossk }+2]} \\
\mathbf{P}_{\text {Sloss }[\mathrm{k}+2]} \\
\mathbf{P}_{\text {Closs }[\mathrm{k}+2]} \\
\hline
\end{array} \\
& \begin{array}{|c|}
\hline \begin{array}{c}
\text { Second Step of } \\
\text { Prediction } \\
\mathbf{e}_{\mathrm{d}, \mathrm{j}} \mathbf{e}_{\mathrm{q}, \mathrm{j}} \\
\mathbf{j}=\mathbf{1 . . 7}
\end{array} \\
\hline
\end{array} \\
& \begin{array}{|c|}
\hline \begin{array}{c}
\text { Vector Couple Choice } \\
\text { and Duty-Cycles } \\
\text { Calculation }
\end{array} \\
\hline \begin{array}{c}
\text { PWM } \\
\text { Modulation }
\end{array} \\
\hline
\end{array}
\end{aligned}
$$

Fig. 3. Block scheme of the control strategy.
The parameter $T_{t}$ represents the period of time in which the reference value has to be reached. Consequently, it takes into account the dynamics of the control action. It has to be underlined that this parameter acts only on the power that in the proposed control strategy is required by the capacitor to increase the voltage at its terminals. When the measured voltage enters a close range of the reference value, the control dynamics is reduced increasing the value of $T_{t}$, in order to significantly decrease the voltage ripple around the voltage reference value and thus improve the phase currents waveform. An appropriate value of $T_{t}$ should be selected based on the desired trade-off between current waveforms quality, steady state error on the DC voltage reference and DC voltage ripple. Once that the current references have been determined, the control actions are chosen on the basis of the mathematical procedure previously introduced. A simplified scheme of the proposed control strategy is presented in Fig. 3.

\section{Simulation Results}

Preliminary results have been achieved through a simulation model implemented in the Matlab/Simulink environment. The system parameters are shown in Table 1. Typical issues of real implementation have been considered in the simulation, such as delay time on the application of the control action (finite time of the calculation) and parasitic elements such as losses related to the power devices of the three-phase inverter and the electrical machine operated as generator.
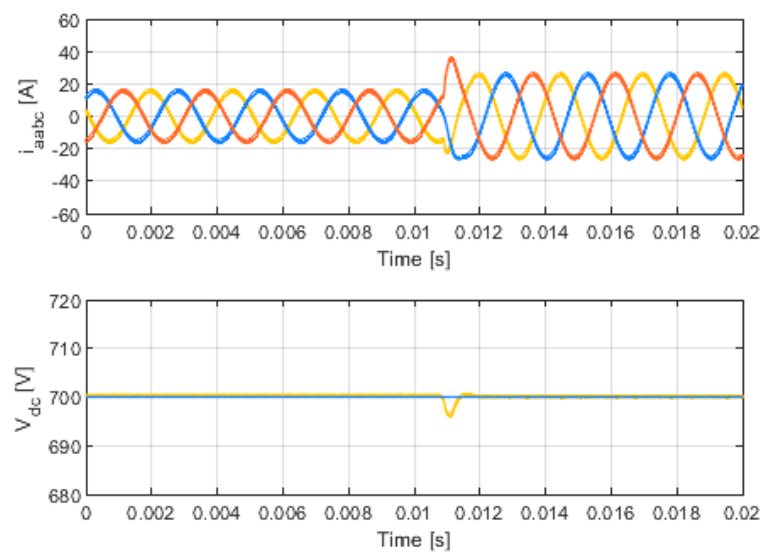

Fig. 4. Phase currents and DC voltage when load resistance is decreased from. . ( $\left.\mathrm{R}_{\text {load }} \approx 200 \Omega, \mathrm{R}_{\text {load }} \approx 120 \Omega, \mathrm{n}_{\mathrm{m}} \approx 2000 \mathrm{rpm}\right)$
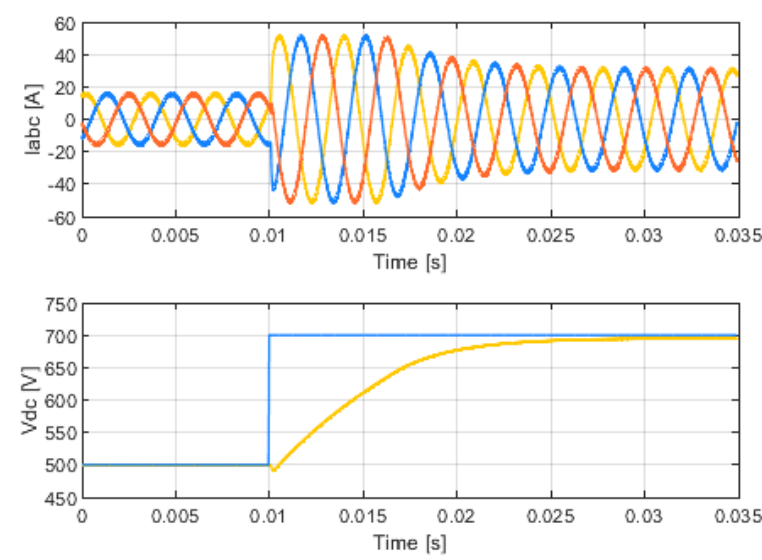

Fig. 5. Phase currents and DC voltage during a reference voltage step $\left(\mathrm{R}_{\text {load }} \approx 150 \Omega, \mathrm{n}_{\mathrm{m}} \approx 1450 \mathrm{rpm}\right)$. 


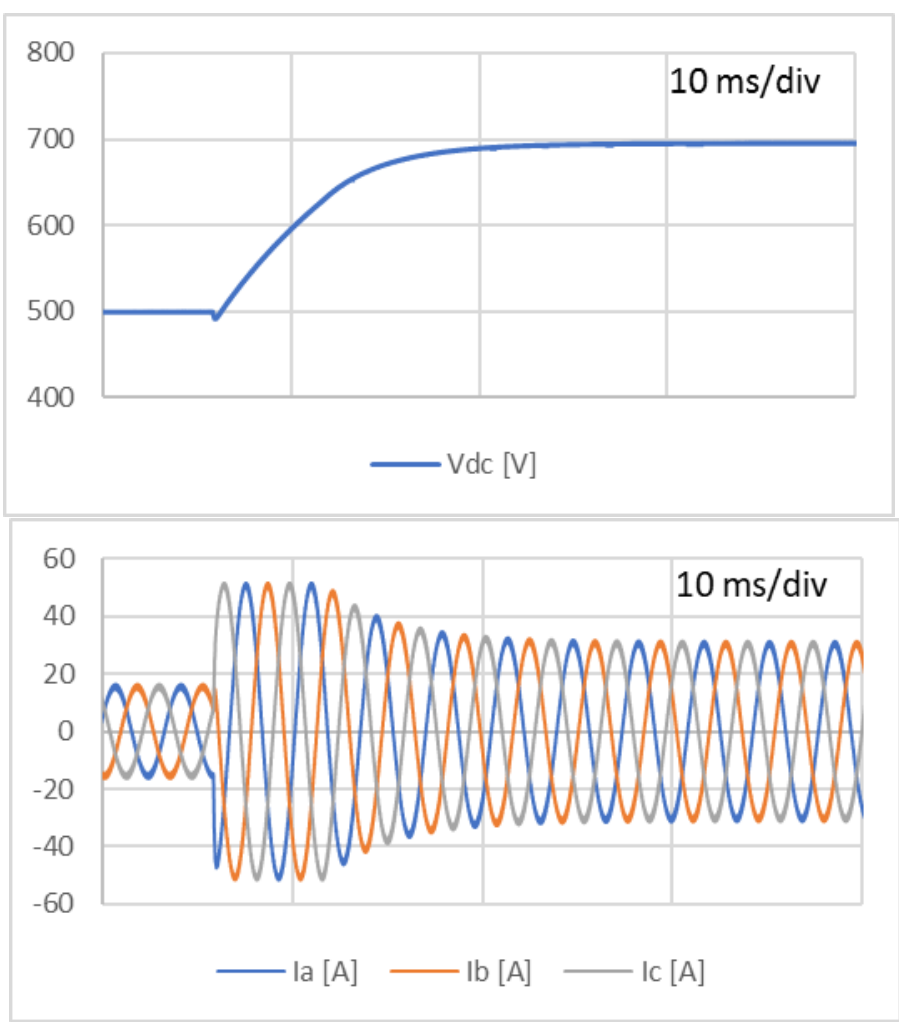

. 6. Co-Simulation. DC-link voltage (top) and phase currents (bottom) during ference voltage step. $\left(\mathrm{R}_{\text {load }} \approx 150 \Omega, \mathrm{n}_{\mathrm{m}} \approx 1450 \mathrm{rpm}\right)$.

\section{A. Co-Simulation}

Between the simulation and the experimental stage, the NI LabVIEW Multisim Co-simulation tool has been used to verify the correct FPGA implementation of the control strategy. This tool allows simulating the physical system through NI Multisim and simultaneously implement the control strategy writing the FPGA code on LabVIEW FPGA. Proceeding like that, it has been possible to significantly reduce the time needed to reach a correct FPGA implementation of the code and thus the experimental stage. The tool highlighted in Fig. 8, thanks to the use of a Control and Simulation Loop guarantees the right timing between the simulation of the physical system and that of the simulated control platform. Only few minor changes to the simulated FPGA code have to be made before loading it on the real control platform. For each iteration of the "Control \& Simulation Loop" the Multisim model of the system is

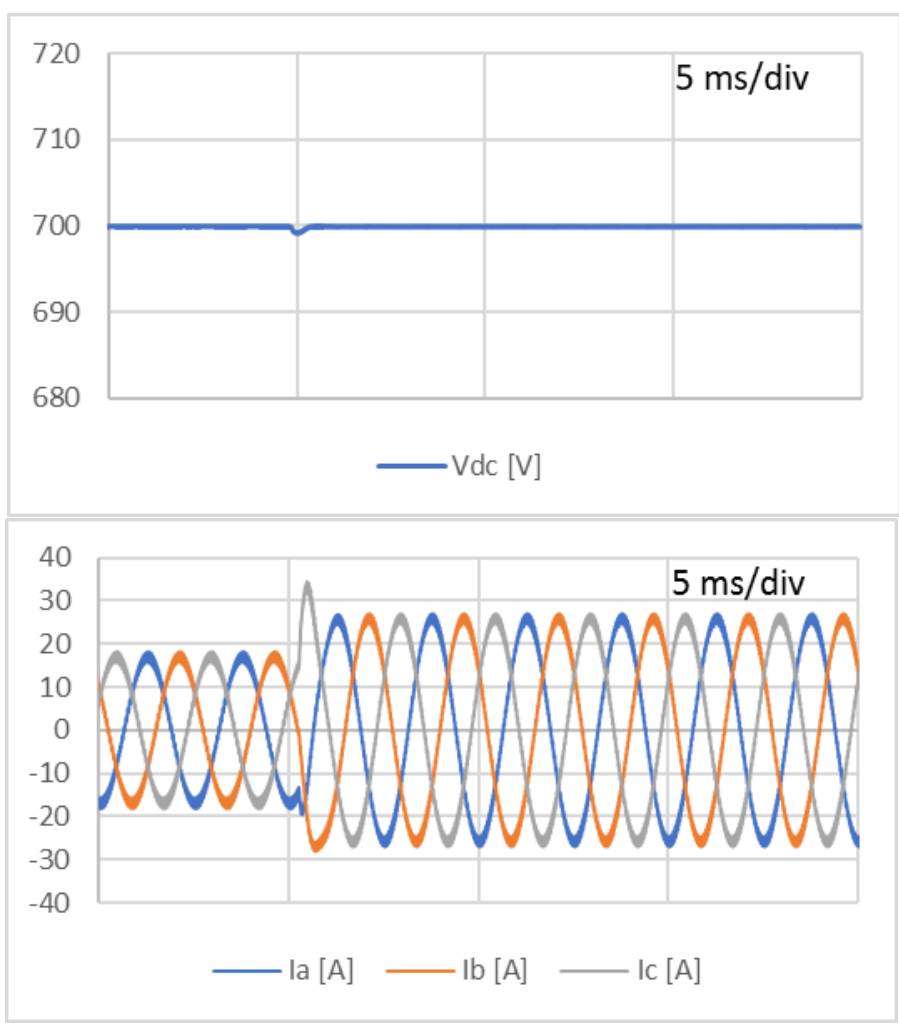

Fig. 7. Co-Simulation. DC-link voltage (top) and phase currents (bottom) w the load resistance is decreased. $\left(\mathrm{R}_{\text {load }} \approx 200 \Omega, \mathrm{R}_{\text {load }} \approx 120 \Omega, \mathrm{n}_{\mathrm{m}} \approx 2000 \mathrm{rpm}\right)$

executed, while the output values of the FPGA simulated code are returned each Ts (i.e. control algorithm sampling time).

TABLE I - SIMULATION, CO-SIMULATION AND EXPERIMENTAL SET-UP MAIN PARAMETERS

\begin{tabular}{|c|c|}
\hline $\mathrm{f}_{\mathrm{el}, \mathrm{nom}}=1200 \mathrm{~Hz}$ & $\mathrm{n}_{\text {nom }}=6000 \mathrm{rpm}$ \\
\hline $\mathrm{L}_{\mathrm{q}}=\mathrm{L}_{\mathrm{d}}=0.450 \mathrm{mH}$ & $\lambda_{\mathrm{pm}}=0.04386 \mathrm{~Wb}$ \\
\hline $\mathrm{C}=250 \mu \mathrm{F}$ & $\mathrm{R}_{\mathrm{s}}=0.1 \Omega$ \\
\hline $\mathrm{T}_{\mathrm{s}}=50 \mu \mathrm{s}$ & PMSG Pole Pairs $=12$ \\
\hline $\mathrm{T}_{\mathrm{t}}=7.5 \mathrm{~ms}$ & $\mathrm{I}_{\text {nom,pk }}=50 \mathrm{~A}$ \\
\hline
\end{tabular}

Co-simulation has been carried out considering the same parameters of the simulation stage. A dead-time of $1 \mu \mathrm{s}$ was added to the switches behavior. The PMSG is rotating at a constant speed, about $1450 \mathrm{rpm}$ which leads to a frequency of the electrical quantities around $290 \mathrm{~Hz}$. For the behavior of the control algorithm during a step in the voltage reference, as shown in Fig. 5 and in Fig. 6, analogous performances have

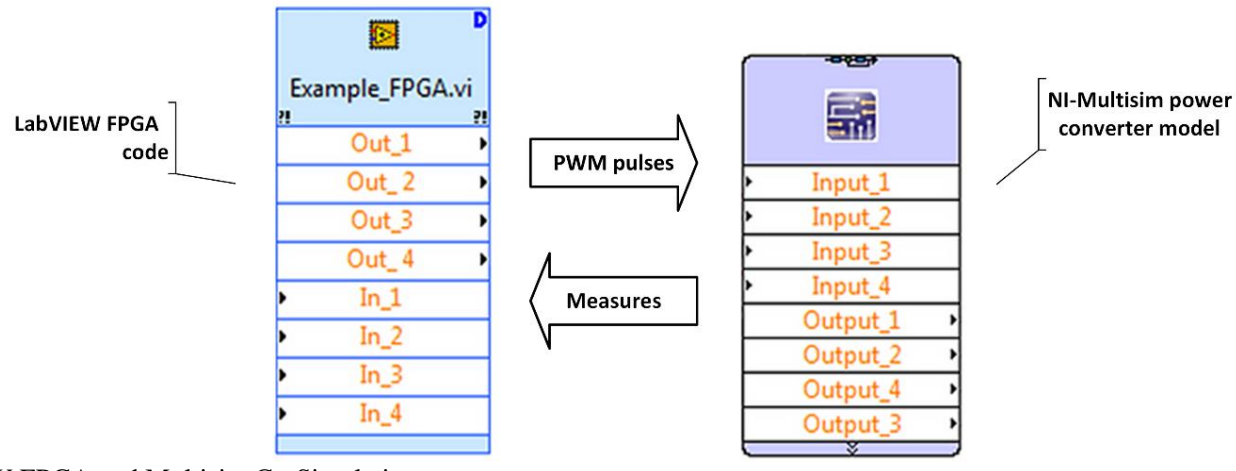

Fig. 8. NI LabVIEW FPGA and Multisim Co-Simulation. 
been put in evidence by both simulation and Co-simulation. Indeed, in both cases, it takes a time equal to about $15 \mathrm{~ms}$ for the control algorithm to reach the new reference value. In order to avoid too high transient currents, a limitation in the value of the q-axis current $\left(i_{q}\right)$ intervenes as it is possible to notice in both figures. In this case, the current limitation was set to $50 \mathrm{~A}$. Again, when the load resistance was decreased from $200 \Omega$ to $140 \Omega$, simulation and Co-simulation returned comparable results as shown in Fig. 4 and Fig. 7. Once again, the fast dynamics of the control allows to keep the DC voltage close to the reference value, even during the fast variation of the load conditions.

As already mentioned, this dynamic is regulated by the parameter $T_{t}$, which allows to increase or decrease the period of time in which the reference voltage has to be reached. By the way, this parameter acts only on the power flow that is delivered to the capacitor and not on the total power produced by the PMSG. The previous considerations have been taken into account to select an appropriate value of $T_{t}$ once that the characteristics of the controlled system have been evaluated. In addition, $T_{t}$ is expressed as an integer multiple of the sampling period. The chosen value of $T_{t}$ for both simulation and Co-simulation is reported in Table I.

\section{EXPERIMENTAL RESULTS}

The developed control strategy has been implemented on the National Instruments System-on-Module (formally sbRIO9651), with a dedicated control board (PED-Board $®)$. The whole control algorithm is developed on the FPGA while the Real-Time target takes into account the external communication and the system management actions. The active rectifier is a $\mathrm{SiC}$ power converter based on the SKiiP 26ACM12V17 from Semikron, that allows to achieve high switching frequencies, improving power quality of the phase currents. The entire electrical drive is shown in Fig. 9.

Calculation of the system losses has been implemented using the same development environment adopted for the MPC algorithm. A dedicated LabVIEW subVI has been deployed to evaluated in real-time the complete system losses. Such a software structure runs on the Real-Time target (i.e. control board $\mu$ Processor) allowing to monitor the behaviour thanks to a dedicated graphical user interface. Table II illustrates the accuracy of the losses estimation algorithm $\left(\mathrm{P}_{\text {Ltot }}\right)$ with respect to an industrial measurement $\left(\mathrm{P}_{\text {LtotM }}\right)$ setup composed by a power meter (PM3000A from Voltech) and a torque-meter (DRFL-II-50 manufactured by ETHMesstechnik). Comparison has been reported with respect to different operating points expressed as DC-bus power $\left(\mathrm{P}_{\mathrm{DC}}\right)$, modulation index $(\mathrm{m})$, and mechanical speed $\left(\Omega_{\mathrm{m}}\right)$.

TABLE II - COMPARISON BETWEEN ESTIMATED AND MEASURED LOSSES

\begin{tabular}{|c|c|c|c|c|}
\hline $\begin{array}{c}\mathrm{P}_{\mathrm{DC}} \\
{[\mathrm{W}]}\end{array}$ & $\mathrm{m}$ & $\begin{array}{c}\Omega_{\mathrm{m}} \\
{[\mathrm{rpm}]}\end{array}$ & $\begin{array}{c}\mathrm{P}_{\text {LtotM }} \\
{[\mathrm{W}]}\end{array}$ & $\begin{array}{c}\mathrm{P}_{\text {Ltot }} \\
{[\mathrm{W}]}\end{array}$ \\
\hline 1040 & 0,19 & 974 & 84.4 & 63.2 \\
\hline 1457 & 0,19 & 974 & 103.7 & 100.5 \\
\hline 3014 & 0,49 & 1945 & 142.2 & 127.5 \\
\hline 4955 & 0,74 & 2995 & 153.3 & 137.7 \\
\hline 5785 & 0,88 & 3332 & 144.1 & 138.5 \\
\hline
\end{tabular}

Fig. 10 shows the steady state behaviour of the control algorithm when the voltage reference is $700 \mathrm{~V}$, the load resistance is equal to about $50 \Omega$ and the value of the $T_{t}$ parameter is set to $7.5 \mathrm{~ms}$. The electrical quantities frequency is about equal to $500 \mathrm{~Hz}(2500 \mathrm{rpm})$. The Total Harmonic Distortion of the phase currents $\left(\mathrm{THD}_{\mathrm{I}}\right)$ has been calculated to be equal to $4.2 \%$.

Dynamic test in Fig. 11 has been performed varying the resistive load from about $200 \Omega$ to about $120 \Omega$ using a DC contactor. It can be noticed how fast is the controller to compensate any DC-bus voltage unbalance. In fact, the phase current is suddenly increased as soon as the required power increases.

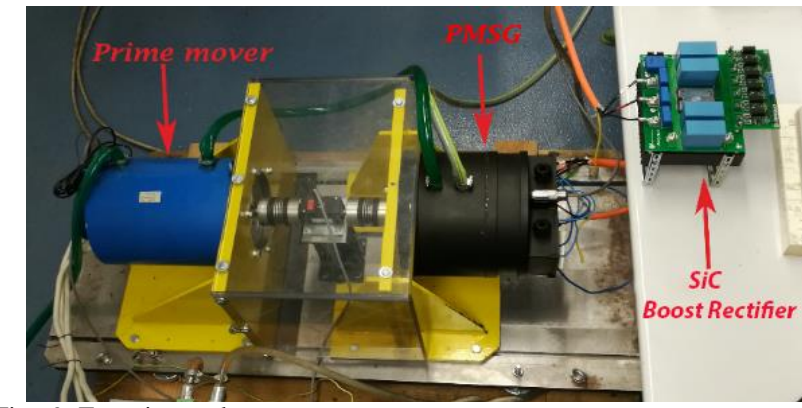

Fig. 9. Experimental setup.

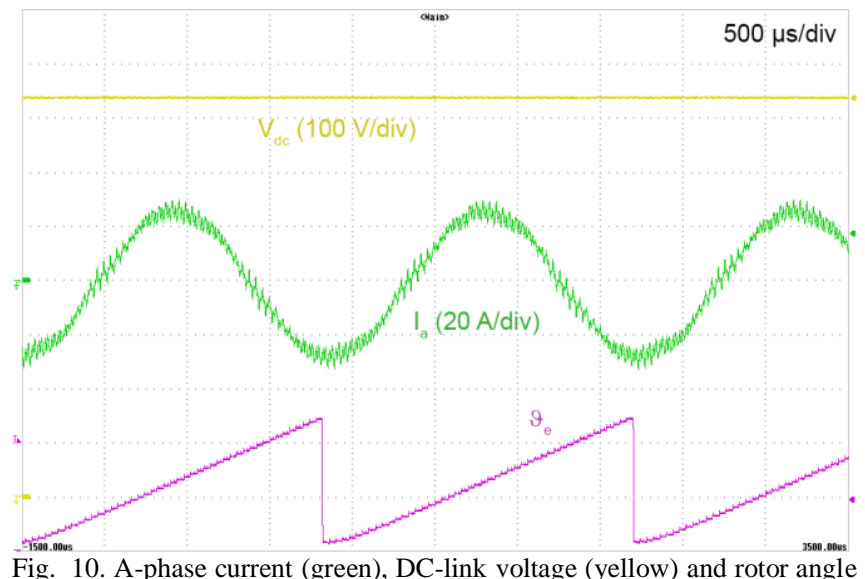

Fig. 10. A-phase current (green), DC-link voltage (yellow) and rotor angle (pink) at steady state. $\mathrm{R}_{\text {load }}=50 \Omega, \mathrm{n}_{\mathrm{m}}=2500 \mathrm{rpm}$.

Fig. 12 shows a zoom of the DC-link voltage of Fig. 11 after the load step. In order to properly show the zoomed voltage waveform, an offset function of the oscilloscope has been exploited. This allows to set the vertical axis zero to $610 \mathrm{~V}$. It is possible to recognize a negligible steady-state error of about $4 \mathrm{~V}$, which indicates the accurate tracking of the voltage reference.

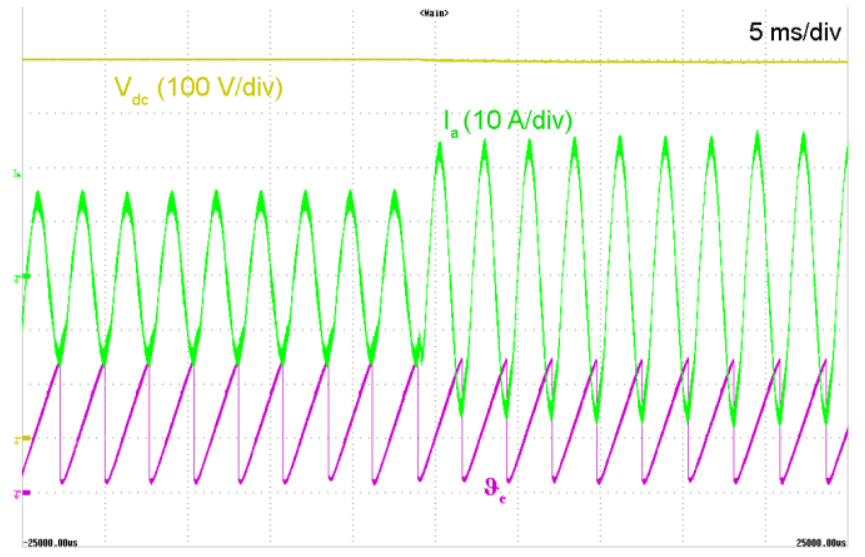

Fig. 11. Resistive load step. Constant $\mathrm{T}_{\mathrm{t}}$. Losses evaluation fully enabled. $\left(\mathrm{R}_{\text {load }} \approx 200 \Omega, \mathrm{R}_{\text {load }} \approx 120 \Omega, \mathrm{n}_{\mathrm{m}} \approx 2000 \mathrm{rpm}\right)$. 


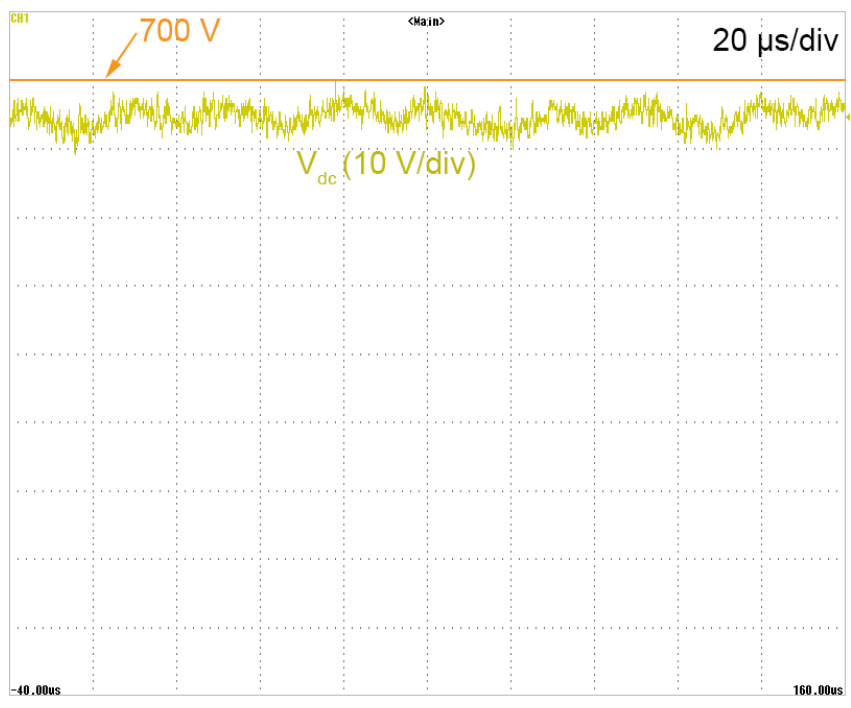

Fig. 12. Zoom of the DC-link voltage in the operating condition of Fig. 11 after the load step.

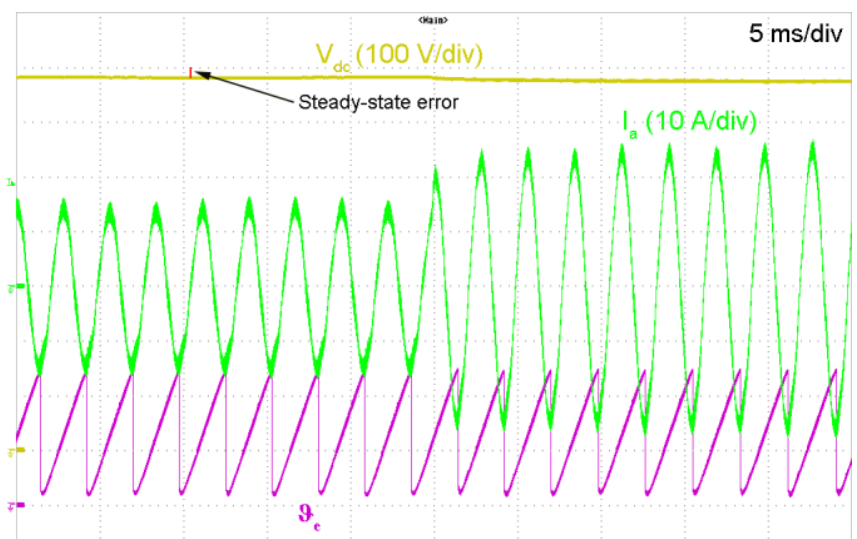

Fig. 13. Resistive load step. Constant $\mathrm{T}_{\mathrm{t}}$. Losses evaluation disabled. $\left(\mathrm{R}_{\text {load }} \approx 200 \Omega, \mathrm{R}_{\text {load }} \approx 120 \Omega, \mathrm{n}_{\mathrm{m}} \approx 2000 \mathrm{rpm}\right)$.

Thus, the error between the voltage reference and the measured one is about equal $0.6 \%$. Furthermore, it can be seen that a peak-to-peak DC-link voltage ripple of about $8 \mathrm{~V}$ is present. In Fig. 13 the same experimental test has been performed when the on-line losses evaluation is completely disabled. It can be noticed that a steady-state error is still present, increasing when the demanded power increases. In fact, during the experimental test both the electrical machine and the inverter losses have been forced to zero, avoiding their contribution in the Model Predictive algorithm. The resulting voltage error is about $24 \mathrm{~V}, \approx 3 \%$. A performance comparison test has been also performed with respect to a variation of the mechanical speed. Speed reference of the prime mover is suddenly changed of about $500 \mathrm{rpm}$ and, after a certain amount of time, it is brought back to its initial value. Fig. 14 shows the results when the algorithm for on-line losses evaluation is enabled. It can be seen that the DC-bus does not exhibit appreciable changes. Whereas, in Fig. 15 the same test is carried out when the losses evaluation was disabled. A steady-state error in the DC-link voltage is present and it depends by the mechanical speed. In Fig. 16 the DC-link voltage reference is suddenly changed from 500 $\mathrm{V}$ to $700 \mathrm{~V}$. The voltage vertical axis zero is set to $250 \mathrm{~V}$. Voltage regulation tries to reach the desired final voltage as soon as possible, increasing the q-axis current reference, theoretically, without any limitation.

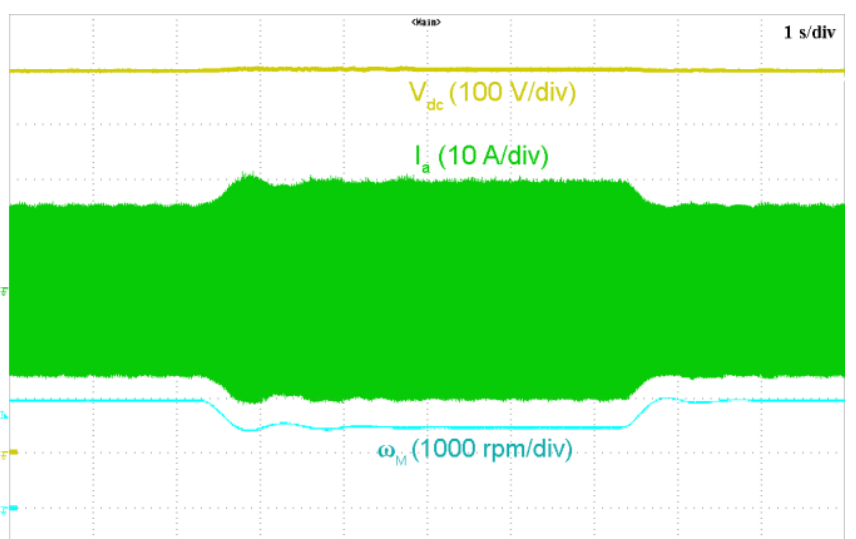

Fig. 14. DC-bus voltage regulation with respect to mechanical speed variation. Losses evaluation fully enabled. $R_{\text {load }} \approx 200 \Omega$.

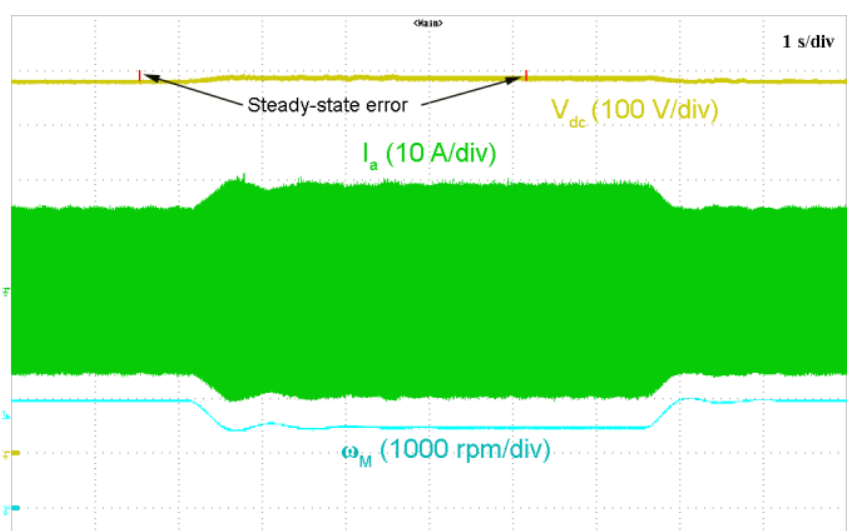

Fig. 15. DC-bus voltage regulation with respect to mechanical speed variation. Losses evaluation disabled. $\mathrm{R}_{\text {load }} \approx 200 \Omega$.

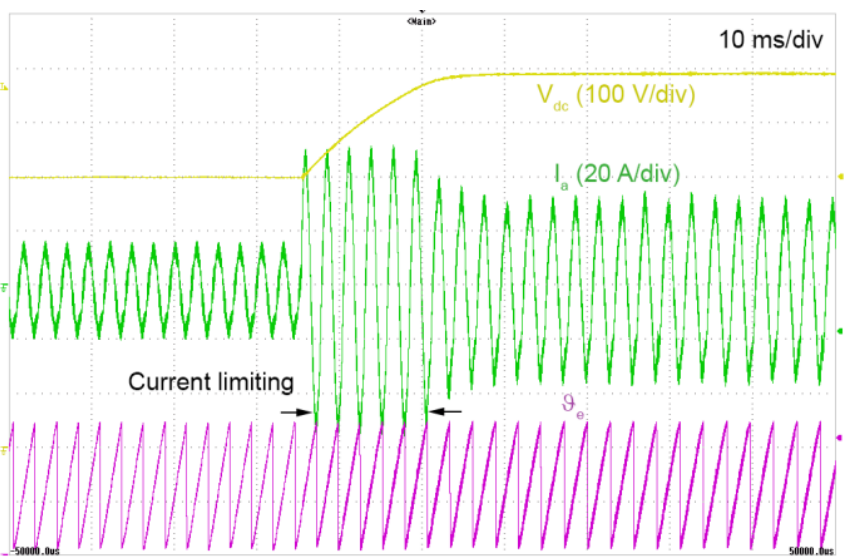

Fig. 16. DC-link voltage reference variation and current limiting feature. $\left(\mathrm{R}_{\text {load }} \approx 140 \Omega, \mathrm{n}_{\mathrm{m}} \approx 1450 \mathrm{rpm}\right)$.

However, the inherent current limiting feature allows to directly saturate the maximum current to the desired value as it is shown in this experimental verification. Of course, any current limitation affects the dynamic related to the tracking of the voltage reference variation.

\section{A. Considerations about the convergence time $T_{t}$}

The convergence time $T_{t}$ is expressed in seconds, and it could be considered as a sort of time required to provide the necessary amount of energy to the DC-link capacitors, in order to bring the related voltage to the desired value. Hence, it directly affects the AC to DC transferred power: lower $T_{t}$ results in high power in short time (i.e. fast compensation of DC-bus voltage unbalances), whereas higher values yield 
longer compensation times with very stable behavior. In general, it is convenient the evaluation of $T_{t}$ as the samples with respect to the control algorithm sampling time $T_{s}$, $T_{t}=\mathrm{H} \cdot T_{s}$.

The effects of the time $T_{t}$ are highlighted in Fig. 17, where two different values are used. Sampling time $\mathrm{T}_{\mathrm{s}}$ has been set to $50 \mu \mathrm{s}$ as reported in Table I. For $T_{t}=T_{t 1}=50 T_{s}$, it can be noticed an initial instability on the generator phase current where also the current waveform appears distorted: current regulation starts becoming ineffective. On the contrary, when the convergence time is increased $T_{t I}=200 T_{s}$, the system is perfectly stable showing a current waveform with low distortion ( $\mathrm{THD}_{\mathrm{I}} \approx 4.2 \%$ ). According to that, the time $T_{t}$ has been dynamically adjusted with respect to the DC-bus voltage error to obtain a high-quality current waveform and accurate DC-bus voltage regulation during the steady-state operation; as well high dynamic, fast, compensation of DC voltage errors when the operating conditions change.

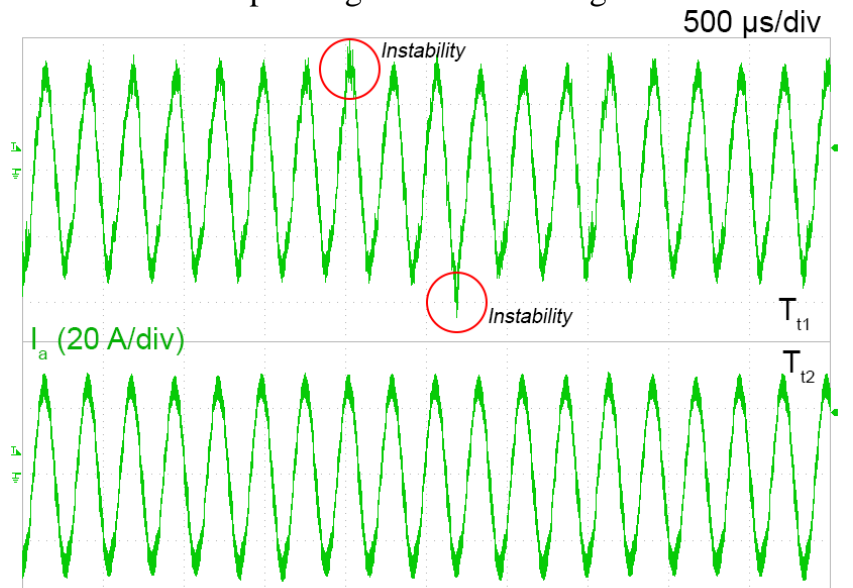

Fig. 17. Effects of the convergence time on the current behavior. $\mathrm{T}_{\mathrm{t} 1}=50 \mathrm{~T}_{\mathrm{s}}$, $\mathrm{T}_{\mathrm{t} 2}=200 \mathrm{~T}_{\mathrm{s}} . \mathrm{R}_{\text {load }} \approx 140 \Omega, \mathrm{n}_{\mathrm{m}} \approx 1450 \mathrm{rpm}$.

Coefficient $\mathrm{H}$ has been evaluated to be proportional to the voltage error expressed as the difference between the DC-link voltage reference and the predicted DC voltage at the step $k+1$ (one step ahead). This approach allows to increase the dynamic of the control actions proportionally to the distance of the current system operating point to the desired state. This is a great benefit that can be obtained by modifying the sole parameter that can be selected in the proposed control structure. In fact, it can be observed that a special, complex, and mathematically complicated tuning is not necessary, being the convergence time $T_{t}$, the single degree of freedom of the system controller.

In order to further improve the robustness and the performance of the proposed controller, parameter $\mathrm{H}$ can be adjusted with respect to the voltage error. For the system having the parameters shown in Table I, a suitable variation of the $\mathrm{H}$ coefficient is reported in Fig. 18, where smaller values are used when the operating point is far from the desired one, resulting in a higher control dynamic. On the other hand, higher values of $T_{t}$ are recommended during the steady state condition (i.e. small DC-bus voltage error), increasing the system stability. The main effect of $T_{t}$ is on the value of the $i_{q}$ reference that is computed according to equation (10). For a fixed deviation of the measured voltage from the reference value, whenever the $T_{t}$ value is such that the computed $i_{q}$ reference is higher than the nominal current of the system, then current limitation sets in and the dynamics of the control depends on the value of the current limitation itself. If the $T_{t}$ value is set such that the current reference is below the current limit, the dynamics of the control depends on the electrical time constant of the generation system. It is understood that an upper limit on the bandwidth is imposed by the control period $\left(T_{s}\right)$, from which depends the update rate of the $i_{q}$ reference. From this perspective, it takes on particular importance to underline that the developed algorithm allows to compute a continuous voltage vector as a control action, keeping low the number of necessary calculations and making possible to increase the speed of the control algorithm. Furthermore, as long as the frequency of the control loop increases, the accuracy of the linear superposition at the basis of the mathematical procedure increases, improving the performance of the control algorithm. As can be seen from Table I, the L/R time constant of the electric machine used for the experimental campaign is about $4.5 \mathrm{~ms}$ considering the rated parameters. In general, it is not recommended to force a convergence time which is far below the electrical time constant due to the constraint imposed by the converter sampling and switching frequency.

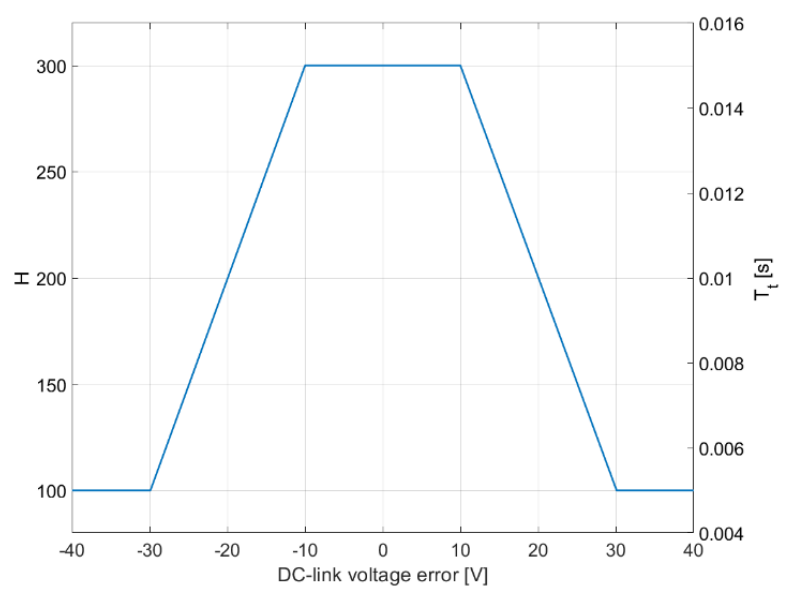

Fig. 18. Behaviour of the convergence term $\mathrm{H}$.

\section{CONCLUSIONS}

The Modulated Optimal Model Predictive Control for the control of the active rectifier that is supplied by a permanent magnet synchronous generator has been presented. The proposed strategy ensures both the fast dynamics of the FiniteSet MPC and good phase currents quality at steady state, which is typical of the control typologies characterized by the presence of a modulator. It has been individuated the parameter $T_{t}$ which allows properly tune the control action to achieve both fast behaviour at transients and high-quality phase current at steady state.

\section{REFERENCES}

[1] M. J. Melfi, S. Evon, e R. McElveen, «Induction versus permanent magnet motors: For power density and energy savings in industrial applications», IEEE Ind. Appl. Mag., vol. 15, n. 6, pagg. 28-35, 2009

[2] A. Cavagnino, Z. Li, A. Tenconi, e S. Vaschetto, «Integrated generator for more electric engine: Design and testing of a scaledsize prototype», IEEE Trans. Ind. Appl., vol. 49, n. 5, pagg. 20342043, 2013.

[3] M. Cheng e Y. Zhu, «The state of the art of wind energy conversion systems and technologies: A review», Energy Convers. Manag., vol. 88, pagg. 332-347, dic. 2014. 
[4] Q. Wang e S. Niu, «Design, Modeling, and Control of a Novel Hybrid-Excited Flux-Bidirectional-Modulated Generator-Based Wind Power Generation System», IEEE Trans. Power Electron., vol. 33, n. 4, pagg. 3086-3096, apr. 2018

[5] M. Abdelrahem, C. M. Hackl, e R. Kennel, «Finite Position SetPhase Locked Loop for Sensorless Control of Direct-Driven Permanent-Magnet Synchronous Generators», IEEE Trans. Power Electron., vol. 33, n. 4, pagg. 3097-3105, apr. 2018.

[6] T. R. S. de Freitas, P. J. M. Menegáz, e D. S. L. Simonetti, «Rectifier topologies for permanent magnet synchronous generator on wind energy conversion systems: A review», Renew. Sustain. Energy Rev., vol. 54, pagg. 1334-1344, feb. 2016.

[7] Z. Zhang, X. Feng, H. Fang, e R. Kennel, «Ripple-reduced model predictive direct power control for active front-end power converters with extended switching vectors and time-optimised control», IET Power Electron., vol. 9, n. 9, pagg. 1914-1923, lug. 2016.

[8] Z. Song, Y. Tian, W. Chen, Z. Zou, e Z. Chen, «Predictive Duty Cycle Control of Three-Phase Active-Front-End Rectifiers», IEEE Trans. Power Electron., vol. 31, n. 1, pagg. 698-710, gen. 2016.

[9] M. Gendrin, J.-Y. Gauthier, e X. Lin-Shi, «A Predictive Hybrid Pulse-Width-Modulation Technique for Active-Front-End Rectifiers», IEEE Trans. Power Electron., vol. 32, n. 7, pagg. 54875496, lug. 2017.

[10] Y. Zhang, Y. Peng, e C. Qu, «Model Predictive Control and Direct Power Control for PWM Rectifiers With Active Power Ripple Minimization», IEEE Trans. Ind. Appl., vol. 52, n. 6, pagg. 49094918, nov. 2016.

[11] E. Jun, S. Kwak, e T. Kim, «Performance Comparison of Model Predictive Control Methods for Active Front End Rectifiers», IEEE Access, vol. 6, pagg. 77272-77288, 2018.

[12] E. Fuentes, C. A. Silva, e R. M. Kennel, «MPC Implementation of a Quasi-Time-Optimal Speed Control for a PMSM Drive, With Inner
Modulated-FS-MPC Torque Control», IEEE Trans. Ind. Electron., vol. 63, n. 6, pagg. 3897-3905, giu. 2016.

[13] L. Bigarelli, A. Lidozzi, M. D. Benedetto, L. Solero, S. Odhano, e P. Zanchetta, «Modulated Optimal Model Predictive Control for Variable Speed Gen-Sets», in 2018 IEEE Energy Conversion Congress and Exposition (ECCE), 2018, pagg. 6859-6865.

[14] H. Yang, Y. Zhang, J. Liang, J. Gao, P. D. Walker, e N. Zhang, «Sliding-Mode Observer Based Voltage-Sensorless Model Predictive Power Control of PWM Rectifier Under Unbalanced Grid Conditions», IEEE Trans. Ind. Electron., vol. 65, n. 7, pagg. 55505560, lug. 2018.

[15] D. Eggers, S. Steentjes, e K. Hameyer, «Advanced Iron-Loss Estimation for Nonlinear Material Behavior», IEEE Trans. Magn., vol. 48, n. 11, pagg. 3021-3024, nov. 2012.

[16] D. Kowal, P. Sergeant, L. Dupre, e L. Vandenbossche, «Comparison of Iron Loss Models for Electrical Machines With Different Frequency Domain and Time Domain Methods for Excess Loss Prediction», IEEE Trans. Magn., vol. 51, n. 1, pagg. 1-10, gen. 2015.

[17] M. Bonislawski e M. Holub, «Averaged inverter loss estimation algorithm», in 2016 18th European Conference on Power Electronics and Applications (EPE'16 ECCE Europe), Karlsruhe, 2016, pagg. 1-9.

[18] C.-Y. Yu, J. Tamura, e R. D. Lorenz, «Optimum DC Bus Voltage Analysis and Calculation Method for Inverters/Motors With Variable DC Bus Voltage», IEEE Trans. Ind. Appl., vol. 49, n. 6, pagg. 2619-2627, nov. 2013.

[19] M. Di Benedetto, A. Lidozzi, L. Solero, F. Crescimbini, e P. J. Grbovic, «Performance assessment of the 5-level 3-phase back to back E-type converter», in 2017 IEEE Energy Conversion Congress and Exposition (ECCE), Cincinnati, $\mathrm{OH}, 2017$, pagg. 2106-2113.

[20] L. Tarisciotti et al., «Model Predictive control for Shunt Active Filters with Fixed Switching Frequency», IEEE Trans. Ind. Appl., vol. 53, n. 1, pagg. 297-304, 2016. 